\title{
EDUCAÇÃO FÍSICA ESCOLAR E MEGAEVENTOS ESPORTIVOS: DESAFIOS E POSSIBILIDADES ${ }^{1}$
}

Jocimar Daolio*

\section{RESUMO}

A partir da definição do objetivo da Escola, este trabalho procura definir o papel da Educação Física escolar no trato com o conteúdo Esporte, fazendo relações com a realização dos chamados megaeventos esportivos. Assume-se que o conteúdo Esporte nas aulas de Educação Física deva ser tratado na perspectiva de atividade de lazer.

Palavras Chave: Educação Física Escolar; Esporte; Megaeventos esportivos.

Nos últimos anos o Brasil assumiu a organização dos chamados megaeventos esportivos ${ }^{3}$ e esse fato, além das justificáveis preocupações de ordem política e econômica, traz à tona uma série de demandas, expectativas, ansiedades e confusões em relação ao papel da Educação Física escolar. Após cada participação brasileira em Jogos Olímpicos, sempre aparecem na mídia e no discurso de representantes das várias esferas do governo demandas em relação à Educação Física escolar, que podem ser traduzidas em perguntas, tais como:

\footnotetext{
1 Este texto foi produzido originariamente para uma participação no Fórum Permanente óMegaeventos Esportivos e Educação Física Escolar: desafios e possibilidades para a escolaò promovido pela Coordenadoria Geral da UNICAMP e realizado em 14 de Maio de 2013.

* Docente da Faculdade de Educação Física da Universidade Estadual de Campinas (Graduação e Pós-Graduação)

2 Este texto foi produzido originariamente para uma participação no Fórum Permanente óMegaeventos Esportivos e Educação Física Escolar: desafios e possibilidades para a escolaò promovido pela Coordenadoria Geral da UNICAMP e realizado em 14 de Maio de 2013.
}

\footnotetext{
${ }^{3}$ Quando são citados os megaeventos esportivos normalmente são considerados apenas os Jogos Olímpicos de 2016, no Rio de Janeiro, e a Copa do Mundo de Futebol, de 2014. Porém lembramos que outros megaeventos também devem fazer parte dessa lista, como os Jogos Mundiais Militares, realizado em 2011, a Copa das Confederações, de 2013, a Copa América de 2015, e os Jogos Paraolímpicos, de 2016.
} 
- é papel da Educação Física escolar detectar talentos esportivos?

- é papel da Escola e da Educação Física escolar formar atletas?

- a Educação Física escolar deve servir como base da pirâmide esportiva nacional?

- A Educação Física pode contribuir para o aumento de medalhas olímpicas do Brasil?

- como tratar o conteúdo Esporte nas aulas de Educação Física escolar?

- há alguma relação entre a Educação Física escolar e os megaeventos esportivos? Se há, como deve ser esta relação?

Essas perguntas são extremamente complexas e, a partir de abordagens teóricas diferentes e com finalidades diferentes, têm composto a pauta das discussões tanto acadêmicas quanto profissionais da área nos últimos anos. Para circunscrever estas questões, a pergunta que me parece inicial e fundamental é:

ñaual o objetivo da Escola como um todo e da Educação Física escolar em particular?ò

A Escola é uma instituição que tem por finalidade a sistematização, organização e transmissão de um conhecimento criado historicamente pelos seres humanos e que deve ser útil para os alunos, a fim de que eles sejam inseridos no universo da vida cultural humana, tenham melhores oportunidades, possam desenvolver toda a potencialidade humana e acessar à condição de cidadãos. De acordo com Fernando González e Paulo Fensterseifer (2009), a escola, como instituição republicana,

[...] tem entre suas funções a de introduzir os alunos no mundo sociocultural que a humanidade tem construído, com o objetivo de que eles possam incluir-se no projeto, sempre renovado, da reconstrução desse mundo. Eles precisam aprender que nesse processo de construção a humanidade tem criado formas de representar o mundo, provisoriamente, mais defensáveis (dado sua universalidade) que outras, e que por isso são privilegiadas no processo de conservação cultural. Também que a humanidade tem promovido formas de convívio social que são mais defensáveis por permitir, entre outras coisas, que as pessoas possam participar/influenciar no processo de tomada de decisão política sobre questões que dizem respeito a todos e, portanto, são mais dignas de serem estimuladas e compreendidas. Finalmente, que a humanidade 
tem construído maneiras de validar essas formas de conhecer e conviver e, portanto, que precisam ser entendidas para continuar perguntando-se sobre o seu valor. Algo como compreender as ñegras do jogoòpara podermos interrogar sua pertinência (p.21-22).

A partir desse objetivo geral da Escola, com o qual concordamos, podese pensar a disciplina escolar Educação Física. De maneira geral, vários autores têm convergido nos últimos anos para uma compreensão de que a Educação Física escolar deve tratar da parte da cultura acumulada pelos seres humanos relacionada às questões corporais.

Um dos primeiros trabalhos brasileiros que estabeleceu o objetivo da Educação Física escolar a partir de uma perspectiva sociocultural foi o livro do COLETIVO DE AUTORES (1992), que o definiu da seguinte forma:

[...] a Educação Física é uma prática pedagógica que, no âmbito escolar, tematiza formas de atividades expressivas corporais como: jogo, esporte, dança, ginástica, formas estas que configuram uma área de conhecimento que podemos chamar de cultura corporal (p.50).

Em outro trabalho (DAOLIO, 2004), também numa perspectiva cultural, escrevi que a Educação Física

[...] pode ampliar seus horizontes, abandonando a ideia de área que estuda o movimento humano, o corpo físico ou o esporte na sua dimensão técnica, para vir a ser uma área que considera o ser humano eminentemente cultural, contínuo construtor de sua cultura relacionada aos aspectos corporais. Assim, a educação física pode, de fato ser considerada a área que estuda e atua sobre a cultura corporal de movimento (p.9).

Mauro Betti e Luiz Roberto Zuliani (2002) afirmam que a finalidade da Educação Física como componente curricular é a de

[...] introduzir e integrar o aluno na cultura corporal de movimento, formando o cidadão que vai produzi-la, reproduzi-la e transformá-la, instrumentalizando-o para usufruir do jogo, do esporte, das atividades rítmicas e dança, das ginásticas e práticas de aptidão física, em benefício da qualidade da vida (p.75)

É nesse sentido que se fala de uma Cultura Corporal ou Cultura de Movimento ou, ainda, Cultura Corporal de Movimento, ou seja, uma tradição acumulada pela humanidade sobre as práticas, conceitos e cuidados corporais. 
A Educação Física, dessa forma, trata pedagogicamente dos elementos dessa parte da Cultura, resumidos nos jogos, esportes, formas de ginástica, lutas e danças, conteúdos que compõem a tradição da área. A intenção última é formar um aluno com conhecimentos desses temas criados pela humanidade, tanto em termos vivenciais como reflexivos. Pretende-se levar os alunos à maior competência sobre esses temas, fazendo com que possam utilizá-los em suas vidas (presente e futura), criticá-los, transformá-los e consumi-los criticamente.

Aqui é possível tirar uma primeira conclusão. Se a Educação Física escolar não contemplar em suas aulas todos os elementos dessa Cultura Corporal de Movimento e tiver apenas o esporte como seu tema de atuação, como muitas vezes acontece, não sobrará tempo para o trato pedagógico com outras formas da Cultura de Movimento, como o jogo, a luta, a ginástica e a dança. Assim, os alunos estarão limitados em seu conhecimento escolar sobre as questões corporais culturais que deveriam ser tratadas pela Educação Física.

Em relação ao conteúdo esporte, objetivo deste texto devido aos megaeventos esportivos realizados e a serem realizados no Brasil, gostaria de utilizar a classificação proposta por Valter Bracht (2005), para tentar delimitar o papel da Educação Física escolar. Segundo o autor, o esporte moderno surgiu a partir de um processo de modificação de elementos da cultura corporal de movimento das classes populares inglesas e também da nobreza inglesa, processo esse que se iniciou em meados do século XVIII e se intensificou a partir do final do século XIX e século XX, combinando suas características com as da nova sociedade urbano-industrial. Os jogos tradicionais foram esvaziados de seus sentidos originais, ligados às festas, colheitas e comemorações, e assumiram as características básicas do esporte, como a competição, o rendimento físico-técnico, a busca do recorde, a racionalização e cientificização do treinamento. Segundo ele, rá cultura corporal de movimento esportivizou-seò (p.15).

Para Bracht (2005, p.16), o esporte pode ser sintetizado em dois modelos:

- esporte de alto rendimento ou espetáculo

- esporte como atividade de lazer 
Em seu resquema dualò o autor não define uma forma de ŕEsporte Escolarò ou îEsporte Educacionalò como categoria, a exemplo do que fazem outros autores e contrariando o que estabelece textos legais ${ }^{4}$. Essa opção do autor deve-se, primeiramente, porque toda prática esportiva (e toda prática humana) é, em si, educacional, restando apenas definir o sentido de educação que se quer dar ao mesmo. Isso não quer dizer que não deva haver intervenção por parte da Escola e do professor de Educação Física em relação ao ensino do esporte. Em segundo lugar, pelo fato de que o esporte que se pratica na Escola (e na Educação Física) será sempre influenciado por um dos modelos acima. Nesse sentido não há um esporte educacional ou esporte escolar em si, já que a forma como se pratica o esporte na escola dependerá do modelo de esporte adotado.

Valter Bracht reconhece que a manifestação de esporte que mais tem fornecido o modelo para a prática esportiva escolar é o de alto rendimento ou espetáculo, trazendo para a Escola valores e códigos inerentes a este modelo, como a seletividade e exclusão, o binômio vitória-derrota, a maximização do rendimento, a utilização de recursos por vezes escusos para se obter a vitória, a violência, a busca somente da técnica eficiente etc.

É nesse sentido que se fala de um Esporte NA Escola ao invés de um Esporte DA Escola. No primeiro caso, Esporte NA Escola, os pressupostos do esporte de rendimento são impostos de forma acrítica na Educação Física escolar, tomando conta das aulas, impondo seus princípios, com a máxima de que os fins justificam os meios. Pode-se chegar à esportivização da Educação Física Escolar, confundindo-se a disciplina escolar com um de seus conteúdos tradicionais, já que esta apenas reproduz os ditames e pressupostos daquele. No segundo caso, Esporte DA Escola, o esporte é um conteúdo que deve atender aos objetivos da Educação Física e da Escola, que deve ser reconstruído, transformado e ressignificado junto aos alunos, a fim de que possa, como conhecimento escolar, ser apropriado por todo o corpo discente.

\footnotetext{
${ }^{4}$ O Decreto 7.984 , de 08/04/13, reconhece três manifestações de esporte, o desporte educacional ou esporte-educação, o desporto de participação e o desporto de rendimento. Sobre o primeiro, afirma: $\tilde{n}$...] praticado na educação básica e superior e em formas assistemáticas de educação, evitando-se a seletividade, a competitividade excessiva de seus praticantes, com a finalidade de alcançar o desenvolvimento integral do indivíduo e a sua formação para o exercício da cidadania e a prática do lazerò
} 
Dessa forma o esporte estará atrelado ao projeto político pedagógico da Escola (VAGO, 1996).

O problema da utilização do modelo do Esporte de Rendimento nas aulas de Educação Física é que esse modelo parece negar princípios fundamentais da instituição escolar, dentre eles o mais importante é a garantia das mesmas oportunidades de conhecimento a todos os alunos. Em relação ao ensino do conteúdo esporte pela Educação Física, nega-se também a oportunidade de acesso dos alunos a outras modalidades esportivas em detrimento de apenas uma; nega-se o conhecimento crítico do esporte em nome da prática de modelos mostrados pela mídia; nega-se a busca de sentimentos de prazer na prática esportiva; nega-se a possibilidade de crítica e transformação do esporte nas aulas, que faz com que a prática esportiva escolar seja diferente daquela praticada fora da escola; nega-se a socialização entre os alunos por meio da prática esportiva; nega-se um conhecimento mais amplo sobre o esporte na sociedade etc.

Outro problema da incorporação do modelo do Esporte de rendimento nas aulas de Educação Física é a r̃̃ontaminaçãoò da pedagogia para a iniciação esportiva. Ou seja, desde os primeiros passos da iniciação esportiva, que deveria contemplar a capacidade de exploração de possibilidades e interesses por parte dos alunos, já se pensa na detecção de futuros talentos, como se fosse possível antever os resultados da iniciação esportiva e como se todos quisessem ou devessem se tornar atletas de alto nível. Em outros termos, ao invés de uma iniciação esportiva geral, já se realiza precocemente uma especialização, reproduzindo o famoso e excludente modelo piramidal de prática esportiva, considerando a Educação Física escolar como a base da pirâmide que deve fornecer elementos necessários para a seleção de praticantes para os níveis superiores, até se chegar a uma elite esportiva. Ao se colocar para a Educação Física escolar a responsabilidade de se constituir como a base da pirâmide esportiva nacional, nega-se seus objetivos de trato com conhecimentos da cultura corporal de movimento.

Imaginem se outras disciplinas escolares fizessem (e às vezes também fazem) a mesma coisa com seus conteúdos. A disciplina de Matemática querendo formar especialistas em matemática, a disciplina de Educação Artística querendo formar artistas, a disciplina de Geografia querendo formar 
geógrafos e assim por diante. A Escola estaria deixando de cumprir sua função precípua que é a disseminação do conhecimento democraticamente e estaria atendendo a poucos alunos.

Outra decorrência que precisa ser enfrentada rápida e corajosamente pela área de Educação Física escolar é a forma como trata as competições esportivas que, na maioria das vezes, reproduz de forma acrítica as competições esportivas adultas, trazendo vícios do modelo esportivo de rendimento que não condizem com os valores que deveriam ser defendidos e praticados pela Educação Física escolar. Recentemente alguns estudos começam a se debruçar sobre a questão das competições esportivas escolares, criticando a implantação nas aulas do modelo do esporte de rendimento e com a intenção de dar a elas outros sentidos atrelados aos objetivos escolares. Riller Reverdito et all (2008) afirmam:

\footnotetext{
Com o propósito de contribuir para o desafio da urgência nas transformações dos modelos de competição, defendemos uma proposta pedagógica para as competições escolares conceitualmente proposta, enquanto evento da escola e integrado ao Projeto PolíticoPedagógico, impregnado com a responsabilidade da educabilidade do sujeito.

Como pilares dessa proposta de competição pedagógica, destacamos os conceitos de cooperação, os valores sociais e a competição de forma interconectada. Para então, sustentar os princípios de totalidade, co-educação, cooperação, participação, autonomia e pluralidade cultural, na análise da organização, das intenções educativas e de sua proposta metodológica (p.43-44).
}

Nesse sentido defendo que a Educação Física escolar utilize o modelo de esporte como prática de lazer, conforme classificação de Bracht (2005) apresentada anteriormente. E aqui precisa ficar claro que não se trata de diminuir o esporte ou reduzi-lo, porque a dimensão do lazer é fundamental na vida dos seres humanos. Não se trata de ñbrincadeirinhaò como muitas vezes se pensa, reduzindo a concepção de lazer para algo menos sério ou não tão necessário na vida das pessoas.

A perspectiva do esporte como atividade de lazer não considera apenas a prática esportiva em locais e momentos de lazer, mas trata-se de uma atividade que pode incorporar outros códigos e valores humanos que não estão presentes no esporte de rendimento, tais como a preocupação com a saúde, o 
bem estar, o prazer da prática, a socialização, a criatividade, o rico encontro entre seres humanos, o riso etc.

A atividade esportiva como prática de lazer também exige educação e essa deve ser tarefa da Educação Física escolar no trato com o conteúdo esporte. Nelson Marcellino (1987) é um dos autores que defende que no lazer há um duplo aspecto educativo, o lazer como veículo e como objeto de educação. É nesse sentido que se fala em educação para o lazer. Muitas vezes, por se entender o lazer como algo menos importante e menos sério, não se acha necessária uma educação específica para o lazer, como se espontaneamente os indivíduos tivessem acesso a ele.

Entendo que o objetivo da Educação Física em relação ao esporte é o de propiciar competência e conhecimento para que os alunos possam utilizar o esporte em suas vidas em seus momentos de lazer, durante e após a fase escolar. Os alunos precisam aprender o esporte, aprender sobre o esporte, aprender com o esporte e aprender para o esporte. Precisam ter um conhecimento mínimo a fim de que possam ser inseridos no mundo da cultura esportiva, como praticantes e como consumidores críticos dessa manifestação. A partir daí, poderão passar a dar mais importância para o esporte em suas vidas, transmitirão isso a seus familiares e amigos, saberão discernir o que é útil e o que deve ser criticado nas informações esportivas oriundas da mídia, saberão reivindicar mais espaços, profissionais, materiais e oportunidades de prática esportiva.

Enfim, se o esporte pode ser bom para alguns, deve ser bom para todos. E aqui vale a pena destacar a grande quantidade de pessoas que estão alijadas da chamada cultura esportiva, que não praticam porque não gostam e não gostam porque não conhecem. Pessoas que não incluem o esporte em seus momentos de lazer e nem o reivindicam como direito do cidadão. Algumas dessas pessoas até consomem o esporte espetáculo transmitido pela mídia e demonstram algum conhecimento a respeito dos códigos próprios da cultura esportiva, mas não o praticam como escolha consciente em seus momentos de lazer.

Podemos fazer um paralelo com outros conhecimentos difundidos pela instituição escolar em outras disciplinas. Por exemplo, as aulas de Literatura devem ter por finalidade o desenvolvimento em todos os alunos de um 
conhecimento que leve ao prazer da leitura de autores antigos e contemporâneos, brasileiros e estrangeiros; as aulas de Educação Artística devem propiciar conhecimentos mínimos que insiram todos os jovens no chamado mundo das artes, em suas várias formas de expressão; as aulas de Ciências devem oportunizar conhecimentos e procedimentos que insiram todos os alunos no mundo científico. E tudo isso visando a formar não somente consumidores de literatura, arte e ciência, mas sobretudo conhecedores e praticantes desses bens culturais criados pela humanidade. É nesse sentido que se defende a educação para a autonomia.

Podemos dizer o mesmo da Educação Física escolar com seus conteúdos jogo, esporte, dança, luta e ginástica. Como todas as outras disciplinas, deve propiciar acesso a um conhecimento específico que leve à ampliação da cultura esportiva, lúdica, gímnica, das danças e das lutas. Um ou outro aluno poderá tornar-se atleta e fazer do esporte sua profissão futuramente, mas a grande maioria deveria ser capaz de utilizar o patrimônio cultural esportivo em atividades de lazer. Além disso, deveria ser melhor conhecedor do fenômeno social esporte, sendo inclusive capaz de consumi-lo criticamente.

Valter Bracht e Felipe Almeida (2003) defendem que o esporte faça parte dos programas de Educação Física na escola, porém destacando que as finalidades da instituição escolar e do sistema esportivo nacional são diferentes. Falam com propriedade de uma rãlfabetização esportivaò como tarefa da Educação Física escolar.

Promover a alfabetização esportiva vai muito além da aprendizagem de destrezas; o exercício da plena cidadania no plano da cultura corporal de movimentos e especificamente no plano do esporte exige o desenvolvimento de competências que vão além dessas habilidades e que abranjam também a capacidade de situar histórica e socialmente essa prática humana, de perceber e analisar os valores que a orientam, os benefícios e os prejuízos de uma ou outra forma da prática esportiva.

Portanto, o esporte escolar só faz sentido se for pedagogizado, ou seja, submetido aos códigos da escola. Em termos mais concretos, isso significa que não basta, para a realização da função da escola, que o esporte seja aprendido e praticado nos seus espaços, é preciso também que o esporte escolar instrumentalize 0 indivíduo a compreender o fenômeno esportivo (p.97-98). 
Nesse sentido, é possível fazer uma relação com o fato de o Brasil sediar megaeventos esportivos. Uma população ativa em termos esportivos, com acesso a boas aulas de Educação Física (sempre é bom lembrar que, de acordo com a Lei de Diretrizes e Bases da Educação Nacional os alunos têm direito a 12 anos de aulas de Educação Física nos ensinos Fundamental e Médio), com capacidade crítica diante da mídia esportiva, politicamente organizada, poderá, a longo prazo, ter mais praticantes, mais atletas e até mesmo alguns atletas de alto nível com destaque no cenário mundial. Da mesma forma que uma população ativa em termos artísticos terá mais artistas e até alguns em nível internacional. Podemos pensar desta forma em todas as áreas.

Fernando Mascarenhas (2012) é crítico em relação às ações governamentais voltadas para a organização e realização dos megaeventos esportivos no Brasil. Em relação à Educação Física escolar também considera danosa a retomada da ideia de pirâmide esportiva e alerta para os perigos em relação à perda do projeto político-pedagógico da Educação Física para o esporte de rendimento.

\begin{abstract}
Há de se dizer que os objetivos da Educação Física devem ser os objetivos da escola e não de políticas e interesses transitórios e externos à sua realidade, como o demandado pelos megaeventos esportivos, em especial, pelo projeto olímpico. Deste modo, o esporte não pode ser confundido com Educação Física, mas deve ser compreendido apenas como um dos seus elementos, junto com a ginástica, o jogo, a dança, a luta, dentre outras práticas corporais produzidas pela humanidade (MASCARENHAS, 2012, p.60).
\end{abstract}

Em relação ao papel dos professores de Educação Física diante do investimento governamental na prática esportiva escolar, que por certo ocorrerá com a intenção de comprometer a Educação Física nesse empreendimento esportivo nacional, o autor considera importante o papel dos professores.

Vale mencionar que não subestimo a capacidade reativa e poder refratário dos professores e da escola em relação ao projeto olímpico. Quero dizer com isso que, como contradição em processo, as políticas e ações governamentais voltadas ao esporte escolar, com rebatimento para a disciplina pedagógica Educação Física, podem até ser bem recebidas, dada a escassez de estrutura e recursos do sistema público de ensino, mas podem também ser parcial ou 
totalmente re-significadas. Sua concretização e efetividade estará condicionada à experiência comum compartilhada pelos sujeitos da escola, que podem se contrapor aos valores e interesses propagados pelo ME e MEC (MASCARENHAS, 2012, p.61).

Enfim, o risco da realização dos megaeventos esportivos, da forma como temos visto sua concepção e organização, é gerar uma população passiva que apenas consuma os espetáculos esportivos e os produtos a eles associados de forma acrítica, sem possibilidade de maiores conhecimentos e, sobretudo, de prática. Nesse sentido o esporte não estaria sendo socializado a toda a população, que, aliás, contribui com o pagamento de impostos para a realização dos megaeventos esportivos.

Esta se constitui, em minha opinião, a tarefa urgente e fundamental da Educação Física escolar: diante do fato de que os megaeventos esportivos estão mesmo acontecendo, os professores da área devem assumir esse tema em suas aulas, não no sentido de reproduzir o ufanismo acrítico propalado pela mídia, mas de estimular junto aos alunos um conhecimento crítico que leve à prática esportiva consciente e transformadora. Como mediadores pedagógicos que são, os professores de Educação Física atualizam significados junto com seus alunos, desconstroem visões de senso comum e reconstroem e ampliam outras formas de compreensão em relação aos conteúdos da área. Nesse sentido é possível esperar que, a partir da mediação da Educação Física escolar, a compreensão e a relação dos alunos com os megaeventos esportivos será qualificada.

\section{Referências}

BETTI, Mauro; ZULIANI, Luiz R. Educação física escolar: uma proposta de diretrizes pedagógicas. Revista Mackenzie de Educação Física e Esporte, São Paulo, V.1, N.1, 2002, p.73-81.

BRACHT, Valter. Sociologia crítica do esporte: uma introdução. 3ed. ljuí, Ed. Unijuí, 2005. 
BRACHT, Valter; ALMEIDA, Felipe Q. A política de esporte escolar no Brasil: a pseudovalorização da educação física. Revista Brasileira de Ciências do Esporte, Campinas, V.24, N.3, 2003, p. 87-101.

BRASIL. Decreto 7984, de 8 de Abril de 2013. Regulamenta a Lei № 9.615, de 24 de março de 1998, que institui normas gerais sobre desporto. Disponível em: http://www.planalto.gov.br/ccivil 03/ Ato20112014/2013/Decreto/D7984.htm. Acesso: 07 Jun 2013.

COLETIVO DE AUTORES. Metodologia do ensino de educação física. São Paulo, Cortez, 1992.

DAOLIO, Jocimar. Educação física e o conceito de cultura. Campinas, Autores Associados, 2004.

GONZÁLEZ, Fernando J.; FENSTERSEIFER, Paulo E. Entre o m̃ão maisòe o rãinda nãoà pensando saídas do não ïlugar da EF escolar. Cadernos de Formação RBCE. Campinas, V.1, N.1, 2009, p.9-24.

MARCELLINO, Nelson C. Lazer e educação. Campinas, Papirus, 1987.

MASCARENHAS, Fernando. Megaeventos esportivos e Educação Física: alerta de tsunami. Revista Movimento, Porto Alegre, V.18, N.1, 2012, p.39-67.

REVERDITO Riller S.; SCAGLIA, Alcides J. Competições Escolares: reflexão e ação em pedagogia do esporte para fazer a diferença na escola. Pensar a Prática. Goiânia, V.11, N.1, 2008, p.37-45.

VAGO, Tarcísio M. VAGO. O "esporte na escola" e o "esporte da escola": da negação radical para uma relação de tensão permanente - um diálogo com Valter Bracht. Movimento, Porto Alegre, V.III, N. 5, 1996, p.4-17. 


\title{
SCHOOL PHYSICAL EDUCATION AND MEGA SPORTING EVENTS: CHALLENGES AND OPPORTUNITIES
}

\begin{abstract}
Based on the definition of the purpose of the school, this study aims to define the role of school physical education in dealing with sports contents and their relations with the so-called mega sporting events. It is assumed that the sport as a content of Physical Education classes should be seen from the perspective of leisure activity.
\end{abstract}

Keywords: Physical Education, Sport, sports mega-events.

\section{EDUCACIÓN FÍSICA ESCOLAR Y MEGAEVENTOS DEPORTIVOS: DESAFIOS Y POSIBILIDADES}

\section{RESUMEN}

A partir de la definición del objetivo de la Escuela, este trabajo busca definir el papel de la Educación Física escolar en el trato del contenido Deporte, estableciendo relaciones con la realización de los llamados megaeventos deportivos. Se asume que el contenido Deporte en las clases de Educación Física deba ser tratado desde la perspectiva de actividad de ocio.

Palabras Clave: Educación Física Escolar; Deporte; Megaeventos deportivos.

\section{Endereço para correspondencia:}

Jocimar Daolio

E-mail: jocimar@fef.unicamp.br 